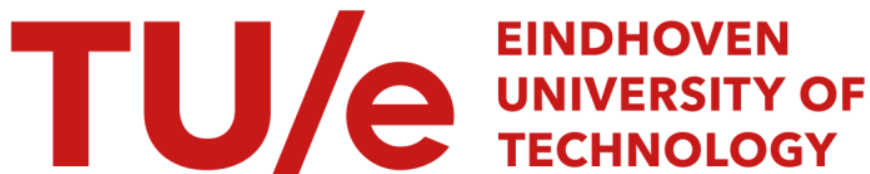

\section{Kinetic aspects of chain growth in Fischer-Tropsch synthesis}

\section{Citation for published version (APA):}

Filot, I. A. W., Zijlstra, B., Broos, R. J. P., Chen, W., Pestman, R., \& Hensen, E. J. M. (2017). Kinetic aspects of chain growth in Fischer-Tropsch synthesis. Faraday Discussions, 197, 153-164.

https://doi.org/10.1039/C6FD00205F

DOI:

10.1039/C6FD00205F

Document status and date:

Published: 01/04/2017

\section{Document Version:}

Accepted manuscript including changes made at the peer-review stage

\section{Please check the document version of this publication:}

- A submitted manuscript is the version of the article upon submission and before peer-review. There can be important differences between the submitted version and the official published version of record. People interested in the research are advised to contact the author for the final version of the publication, or visit the $\mathrm{DOI}$ to the publisher's website.

- The final author version and the galley proof are versions of the publication after peer review.

- The final published version features the final layout of the paper including the volume, issue and page numbers.

Link to publication

\section{General rights}

Copyright and moral rights for the publications made accessible in the public portal are retained by the authors and/or other copyright owners and it is a condition of accessing publications that users recognise and abide by the legal requirements associated with these rights.

- Users may download and print one copy of any publication from the public portal for the purpose of private study or research.

- You may not further distribute the material or use it for any profit-making activity or commercial gain

- You may freely distribute the URL identifying the publication in the public portal.

If the publication is distributed under the terms of Article $25 \mathrm{fa}$ of the Dutch Copyright Act, indicated by the "Taverne" license above, please follow below link for the End User Agreement:

www.tue.nl/taverne

Take down policy

If you believe that this document breaches copyright please contact us at:

openaccess@tue.nl

providing details and we will investigate your claim. 


\section{RSCPublishing Faraday Discussions}

\section{Kinetic aspects of chain growth in Fischer-Tropsch synthesis}

\begin{tabular}{|r|l|}
\hline Journal: & Faraday Discussions \\
\hline Manuscript ID & Draft \\
\hline Article Type: & Paper \\
\hline Date Submitted by the Author: & $\mathrm{n} / \mathrm{a}$ \\
\hline Complete List of Authors: & $\begin{array}{l}\text { Filot, Ivo; Eindhoven University of Techynology, Department of Chemical } \\
\text { Engineering and Chemistry; } \\
\text { Zijlstra, Bart; Eindhoven University of Techynology, Department of } \\
\text { Chemical Engineering and Chemistry } \\
\text { Broos, Robin; Eindhoven University of Techynology, Department of } \\
\text { Chemical Engineering and Chemistry } \\
\text { Chen, Wei; Eindhoven University of Techynology, Department of Chemical } \\
\text { Engineering and Chemistry } \\
\text { Pestman, Robert; Eindhoven University of Techynology, Department of } \\
\text { Chemical Engineering and Chemistry } \\
\text { Hensen, Emiel; Eindhoven University of Techynology, Department of } \\
\text { Chemical Engineering and Chemistry }\end{array}$ \\
\hline
\end{tabular}




\section{Kinetic aspects of chain growth in Fischer-Tropsch synthesis}

Ivo A.W. Filot, Bart Zijlstra, Robin J.P. Broos, Wei Chen, Robert Pestman, and Emiel J.M. Hensen*

Laboratory of Inorganic Materials Chemistry, Schuit Institute of Catalysis, Department of Chemical Engineering and Chemistry, Eindhoven University of Technology, P.O. Box 513, $5600 \mathrm{MB}$, Eindhoven, The Netherlands

E-mail: e.j.m.hensen@tue.nl 


\section{Abstract}

Microkinetics simulations are used to investigate the elementary reaction steps that control chain growth in the Fischer-Tropsch reaction. Chain growth in the FT reaction on stepped Ru surfaces proceeds via coupling of $\mathrm{CH}$ and $\mathrm{CR}$ surface intermediates. Essential to the growth mechanism are $\mathrm{C}-\mathrm{H}$ dehydrogenation and $\mathrm{C}$ hydrogenation steps, whose kinetic consequences have been examined by formulating two novel kinetic concepts, the degree of chain-growth probability control and the thermodynamic degree of chain-growth probability control. For $\mathrm{Ru}$ the $\mathrm{CO}$ conversion rate is controlled by the removal of $\mathrm{O}$ atoms from the catalytic surface. The temperature of maximum $\mathrm{CO}$ conversion rate is higher than the temperature to obtain maximum chain-growth probability. Both maxima are determined by Sabatier behavior, but the steps that control chain-growth probability are different from those that control the overall rate. Below the optimum for obtaining long hydrocarbon chains, the reaction is limited by the high total surface coverage: in the absence of sufficient vacancies the $\mathrm{CHCHR} \rightarrow \mathrm{CCHR}+\mathrm{H}$ reaction is slowed down. Beyond the optimum in chain-growth probability, $\mathrm{CHCR}+\mathrm{H} \rightarrow \mathrm{CHCHR}$ and $\mathrm{OH}+\mathrm{H} \rightarrow \mathrm{H}_{2} \mathrm{O}$ limit the chain-growth process. The thermodynamic degree of chain-growth probability control emphasizes the critical role of the $\mathrm{H}$ and free-site coverage and shows that at high temperature chain depolymerization contributes to the decreased chain-growth probability. That is to say, during the FT reaction chain growth is much faster than chain depolymerization, which ensures high chain-growth probability. The chain-growth rate is also fast compared to chain-growth termination and compared to the steps that control the overall $\mathrm{CO}$ conversion rate, which are $\mathrm{O}$ removal steps for Ru.

Keywords: Fischer-Tropsch, Ruthenium, chain-growth, sensitivity analysis, degree of rate control. 


\section{Introduction}

The widespread availability of cheap natural gas resources in the coming decades in combination with the dwindling supplies of readily available crude oil has led to commercialization of gas-to-liquids (GTL) processes in the fuels and chemicals industry. The Fischer-Tropsch (FT) reaction plays a central role in these GTL efforts: it converts synthesis gas into clean transportation fuels and chemicals. Despite significant research efforts in the last decade, many aspects of the underlying mechanism need to be better understood. Such insight will facilitate the guided design of improved catalysts. Modern approaches such as computational advances and development of model systems are tools that may provide such insights. In this work, we will discuss our recent findings regarding the dominant factors governing the chain growth, one of the essential reaction steps in the FT reaction, for Ru model catalysts.

The FT reaction is a polymerization reaction of $\mathrm{C}_{1}$ monomer species, which are in situ generated on the catalytic surface by $\mathrm{CO}$ dissociation. ${ }^{1-2}$ Chain growth proceeds through association reactions of $\mathrm{C}_{1}$ monomers with growing hydrocarbon chains. Products leave the surface as olefins ( $\beta$-H elimination), paraffins (hydrogenation) or aldehydes (CO insertion). ${ }^{1,}$

${ }^{3}$ Termination of $\mathrm{C}_{1}$ monomers by hydrogenation yields methane, which is an undesired reaction product as it is the source of synthesis gas. In commercial practice, the aim is usually to minimize methane yield and maximize the formation of liquid hydrocarbons that can be converted to transportation fuels in downstream hydrocracking processes. ${ }^{4}$ This can be achieved by increasing the chain-growth probability $(\alpha)$, defined as the rate of propagation $\left(r_{p}\right)$ over the sum of the rates of propagation and termination $\left(r_{t}\right)$.

$\alpha=\frac{r_{p}}{r_{p}+r_{t}}$ 
As termination is slow compared to propagation - a necessary condition to obtain long hydrocarbon chains in the overall FT mechanism -, the chain-growth probability can be raised by lowering the reaction temperature. Consequently, the FT reaction is usually operated below the $\mathrm{CO}$ conversion rate optimum.

Recently, we have explored the mechanism of the FT reaction on Ru surfaces by using microkinetics simulations of $\mathrm{CO}$ hydrogenation involving kinetic parameters of all relevant elementary reaction steps over Ru surfaces determined by density functional theory calculations. ${ }^{5}$ The main findings of this work are as follows. CO hydrogenation on a planar surface of Ru is slow and the main hydrocarbon product is methane. Step-edge sites are required for the FT reaction. The low barrier of $\mathrm{CO}$ dissociation ensures sufficient rapid supply of $\mathrm{C} 1$ monomers to maintain a high rate of chain propagation. On stepped $\mathrm{Ru}$ surfaces, propagation involves $\mathrm{CH}$ surface intermediates so that the initial chain is formed by $\mathrm{CH}+\mathrm{CH}$ coupling and further chain growth involves reaction of $\mathrm{CH}$ with $\mathrm{CR}(\mathrm{R}=$ alkyl $)$ fragments. This implies that chain growth involves hydrogenation and dehydrogenation steps to transform the direct $\mathrm{CHCR}$ coupling product into the $\mathrm{CCH}_{2} \mathrm{R}$ intermediate that can further couple to $\mathrm{CH}$. Further salient details worth mentioning of the mechanism are the reversibility of chain growth, the predominance of olefins as the main hydrocarbon reaction products and the removal of oxygen in the form of water. A mechanism involving $\mathrm{CO}$ insertion into growing chains followed by $\mathrm{C}-\mathrm{O}$ bond scission in $\mathrm{RCO}$ fragments contributes little to the overall FT reaction.

By using the degree of rate control approach ${ }^{6-7}$ and applying linear scaling laws and Brønsted-Evans-Polanyi relationships, characteristic kinetic regimes for the FT reaction were identified as function of metal-carbon and metal-oxygen binding energies. For Ru this leads to three kinetic regimes. ${ }^{5}$ Too weak binding with carbon and oxygen results in $\mathrm{CO}$ dissociation being rate controlling. Too strong binding of oxygen makes water removal the 
most difficult step in the FT mechanism, while to strong binding of carbon shifts the rate controlling step to chain growth. The latter will limit the chain-growth probability. Whilst $\mathrm{Ru}$ operates in the water removal limited regime, the FT reaction on Co is limited by CO dissociation and water removal.

Currently, there is a lack of computational studies that describe in detail the parameters the influence the chain-growth probability. Under the selectivity in the FT reaction is of fundamental importance to improving the current generation of FT catalysts, especially with respect to the question how activity and selectivity are interrelated. Van Santen and coworkers have discussed several aspects about FT selectivity by constructing theoretical models based on the steady-state solutions of coupled rate expressions, Monte Carlo simulations and density functional theory calculations. ${ }^{8-13}$ Understanding chain-growth probability is also important for novel processes such as the conversion of synthesis gas to olefins. The group of De Jong developed an FT process using a modified Fe catalyst that produces selectively lower olefins. ${ }^{14}$ They speculated that such a selectivity is possible by the unique bonding characteristics of an iron-carbide phase as compared to that of metals such as Co or Ru.

In this work, we contribute to the current understanding of the selectivity issues in the FT reaction by exploring the origin of the hydrocarbon selectivity with a focus on chain-growth probability. In particular, we elucidate the elementary reaction steps that control the chaingrowth probability. For this purpose, we introduce a mathematical tool, which is akin to the degree of selectivity concept introduced by Campbell. ${ }^{15-16}$ By analysis of the surface composition, the kinetic network and the individual rates of the elementary reaction steps contributing towards the overall reaction, we can relate the predicted product selectivity, viz. chain-growth probability, to underlying factors that govern these processes. 


\section{Method}

A first-principles microkinetic model to simulate the FT reaction over stepped Ru surfaces was constructed using activation barriers and corresponding vibrational frequencies derived from density functional theory calculations as previously published. ${ }^{5,17}$ From these barriers and frequencies, the forward and backward rate constants for the elementary reaction steps were constructed using the Eyring equation:

$k=\frac{k_{b} T}{h} \frac{Q^{\ddagger}}{Q} e^{-\frac{E_{a}}{k_{b} T}}$

where $k$ is the rate constant, $k_{\mathrm{b}}$ is the Boltzmann constant, $T$ is the temperature in $\mathrm{K}, h$ is Planck's constant, $Q \ddagger$ is the partition function of the transition state complex, $Q$ is the partition function of the complex in the pre-activated (initial) state, and $E_{\mathrm{a}}$ is the electronic activation energy. The partition functions for the activated and pre-activated complexes were taken as the products of the translational, rotational, and vibrational partition functions corresponding to the configurational degrees of freedom of the surface complexes.

For non-activated molecular adsorption, it was assumed that the complex loses one translational degree of freedom with respect to the gas phase in the transition state. The changes in the rotational degrees of freedom were neglected. Accordingly, the following expression was employed for the rate of molecular adsorption:

$k=\frac{P A}{\sqrt{2 \pi m k_{b} T}} S$

where $P$ is the partial pressure of the adsorbate in the gas phase, $A$ is the surface area of the adsorption site, $m$ is the mass of the adsorbate, and $S$ is the sticking coefficient. The surface 
area $A$ was set to the area of a threefold site. The sticking coefficients were set to unity in the current simulations.

For desorption, it was assumed that the complex has three rotational degrees of freedom and two translational degrees of freedom in the activated state, while it has only vibrational degrees of freedom in the adsorbed state. Accordingly, the rate of desorption is given by:

$k=\frac{k_{b} T^{3}}{h^{3}} \frac{A\left(2 \pi k_{b}\right)}{\sigma \theta_{\text {rot }}} e^{-\frac{E_{\text {des }}}{k_{b} T}}$

where $\sigma$ is the symmetry number, $\theta$ is the characteristic temperature for rotation, and $E_{\mathrm{des}}$ is the desorption energy.

The approach for the microkinetics simulations has been extensively described before and is briefly discussed here for clarity. ${ }^{18}$ Differential equations for all surface reaction intermediates were constructed using the rate constants of the elementary steps. Given a system of $N$ elementary reaction steps, $2 N$ rate expressions (i.e., both forward and backward reactions) were obtained with the form:

$r_{j}=k_{j} \prod_{i} c_{i}^{v_{i}^{j}}$

where $c_{\mathrm{i}}$ is the concentration of species $i$ in the elementary reaction step $j$ on the surface, and $v_{i}$ is the stoichiometric coefficient of species $i$ in elementary reaction step $j$. These rate expressions were used to derive an ordinary differential equation for each component on the surface with the form:

$\frac{\mathrm{d} c_{i}}{\mathrm{~d} t}=\sum_{j} v_{i, j} r_{j}$

where $c_{\mathrm{i}}$ is the concentration of species $i$ on the surface, and $v_{i, j}$ is the stoichiometric coefficient of species $i$ in elementary reaction step $j$.

The in-house developed $\mathrm{C}++$ program $\mathrm{MKMCXX}^{19}$ was employed to determine the steadystate coverages by integrating this set of ordinary differential equations with respect to time 
using the backward differentiation formula method. The steady-state surface coverage values were used to compute the rates of the individual elementary reaction steps and the overall rate per active site. 


\section{Result and discussion}

Microkinetics simulations were performed to investigate the influence of the elementary reaction steps on the chain-growth probability $\alpha$. The underlying microkinetic model contains kinetic parameters for elementary reaction steps determined by quantum-chemical DFT calculations for the stepped $\mathrm{Ru}(11 \overline{2} 1)$ surface. ${ }^{5,17}$ The dataset is available in the Supporting Information. The total pressure in the current microkinetics simulations was set to $20 \mathrm{~atm}$ and a $\mathrm{H}_{2} / \mathrm{CO}$ ratio of 2 was used. These conditions are close to the conditions used in commercial practice. First, we will present rates, the chain-growth probability and the product distribution as a function of temperature. Next, we explore the influence of the rates of the elementary reaction steps on the chain-growth probability by modifying the reaction barrier of the elementary reaction steps in the system. This approach is derived from the concept of degree of rate control as introduced by Campbell and co-workers. ${ }^{15-16}$ Next we rationalize these results by relating the variations in chain-growth probability to the rates of the elementary reaction steps and the surface coverages.

We first determined how temperature affects the overall $\mathrm{CO}$ consumption rate (Figure 1a) and the chain-growth probability (Figure 1b). From Figure 1a, it can be seen that the optimum temperature for $\mathrm{CO}$ conversion lies round $650 \mathrm{~K}$, while the optimum reaction temperature for obtaining higher hydrocarbons is below the Sabatier maximum for CO conversion. This is in line with experimental results. ${ }^{1,20-22}$ Figure $1 \mathrm{~b}$ further underpins this interpretation by showing the optimum temperature for chain-growth probability to be around 500 K. This optimum also finds its origin in Sabatier's principle. As we will demonstrate below, the chain growth is limited by hydrogenation, one of the essential steps in the growth mechanism, at low temperature. At high temperature, the reversibility of the chain-growth process is at the origin of the decreased chain-growth probability in addition to faster hydrogenation of chains and $\mathrm{C} 1$ monomers. These two effects also lead to increased methane 
selectivity. An analysis of the degree of rate control with respect to the $\mathrm{CO}$ conversion rate shows that the overall conversion of $\mathrm{CO}$ is limited by water removal from the catalytic surface. While at temperatures below the optimum $\mathrm{O}$ hydrogenation and water desorption are controlling the rate, the rate-controlling step shifts to the reaction of two $\mathrm{OH}$ groups to produce adsorbed water at high temperature.

Figure 2 shows the product distribution in more detail as function of temperature. At the chain-growth probability optimum, the amount of $\mathrm{C}_{40+}$ hydrocarbons is highest. In commercial applications, high chain-growth probability and low methane production is targeted. Therefore, we will focus our more detailed analysis on the influence of the elementary reaction steps on the chain-growth in the temperature regime between $400 \mathrm{~K}$ and $600 \mathrm{~K}$. In order to do so, we first define a degree of chain-growth control (DCGC) as follows:

$\chi_{i, \mathrm{DCGC}}=\left(\frac{\partial \alpha}{\partial \ln k_{i}}\right)_{i \neq j, K_{i}}$

in which $\alpha$ is the chain-growth probability, $k_{i}$ the rate constant of elementary reaction step $i$, and $K_{i}$ the equilibrium constant of elementary reaction step $i$. In essence, DCGC probes the absolute change in chain-growth probability relative to a relative change in the rate constant. We do this by changing the height of the reaction barrier such that the equilibrium constant of the elementary reaction step is not changed. This is done to satisfy the microscopic reversibility condition. We find that the elementary steps that control the overall $\mathrm{CO}$ consumption rate are not necessarily the same as those that control the chain-growth probability.

Figure 3a shows the DCGC for all relevant elementary reaction steps within the chosen temperature range. A positive value for the DCGC value implies that increasing the rate constant of a particular elementary reaction step increases the chain-growth probability and 
vice versa. In the former case, we can say that the elementary reaction step is controlling the chain growth, in the latter case it is inhibiting chain growth. As several elementary reaction steps share similar features, we changed the barriers for all of these steps together in assessing the influence of chain growth. For instance, for evaluation of the influence of monomer insertion into the growing chain on the chain-growth process, we changed the barriers for all $\mathrm{C}$-insertion reactions, instead of changing only one such as that of $\mathrm{C}+$ $\mathrm{CCH}_{2} \mathrm{CH}_{3}$ coupling. The same holds for other $\mathrm{CH}_{\mathrm{x}}$ insertion reactions and chain hydrogenation reactions. The discussion of the results in Figure 3a is supported by the reaction network showing the rates per elementary reaction step (Figure 3b). We first discuss (sets of) elementary reaction steps that lead to an increase of the chain-growth probability. Thereafter, we will discuss the reactions that inhibit the chain-growth probability.

At low temperature, the chain-growth probability is mainly influenced by the $\mathrm{CCHR}+\mathrm{H} \rightarrow$ CHCHR elementary reaction step. From Figure 3b, we infer that this elementary reaction step proceeds in the reverse direction, or in other words, CHCHR is dehydrogenated to CCHR $(\mathrm{CHCHR} \rightarrow \mathrm{CCHR}+\mathrm{H})$. This is in line with the earlier discussed reaction sequence following $\mathrm{CH}$ coupling to $\mathrm{CR}$ surface intermediates as the dominant coupling reaction. ${ }^{5}$ For this reaction to propagate after the $\mathrm{CH}$ insertion reaction, the $\alpha$-carbon atom in $\mathrm{CHCR}$ needs to be dehydrogenated followed by hydrogenation of the $\beta$-carbon to $\mathrm{CH}_{2}$. Thus, dehydrogenation of the $\alpha$-carbon is kinetically important to chain growth. The strong influence of this elementary reaction step below $500 \mathrm{~K}$ is next discussed in terms of the surface coverages (Figure 4) The $\alpha$-dehydrogenation of CHCHR requires a vacant site on the surface. At low temperature, there are almost no free sites, which limits chain growth. The increase in surface vacancies with temperature results in faster $\alpha$-carbon dehydrogenation. Beyond the optimum in chain-growth probability, two other reactions limit the chain growth, namely $\mathrm{CHCR}+\mathrm{H} \rightarrow \mathrm{CHCHR}$ and $\mathrm{OH}+\mathrm{H} \rightarrow \mathrm{H}_{2} \mathrm{O}$. The latter reaction also contributes to 
the control of the overall $\mathrm{CO}$ consumption rate next to $\mathrm{OH}$ hydrogenation and the proton transfer between two $\mathrm{OH}$ groups to form adsorbed water. The barrier for the $\mathrm{CHCR}+\mathrm{H} \rightarrow$ CHCHR reaction is the highest of all kinetically relevant chain-propagation reactions. The $\mathrm{OH}+\mathrm{H}$ reaction is also important as it removes both $\mathrm{O}$ and $\mathrm{H}$ atoms from the surface. Faster $\mathrm{OH}$ hydrogenation results in a lower H coverage. As chain growth is limited by only one hydrogenation step in this regime, whereas it is inhibited by two hydrogenation steps (vide infra), a lower $\mathrm{H}$ coverage results in increased chain-growth probability.

Three elementary reaction steps strongly inhibit chain growth. At low temperature, this is the $\mathrm{CHCHR}+\mathrm{H} \rightarrow \mathrm{CH}_{2} \mathrm{CHR}$ reaction. This steps converts growing hydrocarbon chains that are a part of the dominant chain propagation cycle $(\mathrm{CR} \rightarrow \mathrm{CHCR} \rightarrow \mathrm{CHCHR} \rightarrow \mathrm{CCHR} \rightarrow \mathrm{CR})$, to the $\mathrm{CH}_{2} \mathrm{CHR}$ surface intermediate. This intermediate can readily desorb from the surface as a 1-olefin, in other words it leads to chain-growth termination. With increasing temperature, $\mathrm{CCH}_{2} \mathrm{R}+\mathrm{H} \rightarrow \mathrm{CHCH}_{2} \mathrm{R}$ and $\mathrm{CR} \rightarrow \mathrm{CH}_{2} \mathrm{R}+\mathrm{C}$ reactions become rateinhibiting. Similar to the $\mathrm{CHCHR}+\mathrm{H} \rightarrow \mathrm{CH}_{2} \mathrm{CHR}$ reaction, these two elementary reactions convert intermediates that are part of the chain-growth cycle to intermediates that can desorb from the surface as an olefin, either directly or via two additional hydrogenation steps. At low temperature, these two reactions are not rate-inhibiting for the following reasons. The $\mathrm{CCH}_{2} \mathrm{R}$ $+\mathrm{H} \rightarrow \mathrm{CHR}$ reaction requires at least two additional hydrogenation steps for chain-growth termination. As the surface coverage of $\mathrm{H}$ is relatively low, this chain-growth termination pathway is slow. The $\mathrm{CR} \rightarrow \mathrm{CH}_{2} \mathrm{R}+\mathrm{C}$ is not rate-inhibiting at low temperature, because this reaction requires a surface vacancy which are scarce.

Our analysis of the chain-growth controlling elementary reaction steps in conjunction with the composition of the adsorbed layer reveals the delicate interplay between the coverage of $\mathrm{H}$ and the kinetic network of the growing chains. To further analyze this interplay, we have 
performed a thermodynamic degree of chain-growth control analysis, which we define as follows

$\chi_{i, \mathrm{TDCGC}}=\left(\frac{\partial \alpha}{\partial\left(-\frac{\Delta G}{R T}\right)}\right)_{G_{i \neq j}^{T S}, G_{m}^{0}}$

where $\Delta G$ is the Gibbs Free energy of a specific surface species. ${ }^{15}$ In this case, the surface stability of one particular surface adsorbate is changed, while keeping the height of the activation barrier and the stability of all other species the same. The effect of this change on the chain-growth probability is investigated. A positive value of $\chi_{i, \text { TDCGC }}$ indicates that stabilizing the particular surface species increases chain-growth probability. The results of this analysis are depicted in Figure 5. For the FT process to occur, it is often assumed that a small amount of free sites should be available for CO dissociation, the first step in the overall FT process. We already showed that the FT reaction has several kinetic regimes and the Rucatalyzed FT reaction operates in a kinetic regime, where CO dissociation is not controlling the overall rate. ${ }^{23}$ This is supported by the results in Figure 5, where it can be seen that the surface stability of $\mathrm{CO}$ does not influence the chain-growth probability. The interesting consequence is that, when $\mathrm{CO}$ dissociation is not rate-controlling, an increase in the number of free surface sites does not necessarily increase the overall $\mathrm{CO}$ consumption rate and the chain-growth probability. On contrary, an increased number of free sites on the surface has a negative influence on the chain-growth probability. This is primarily the result of an increased rate of chain depolymerization. The relevant elementary reaction step is $\mathrm{CR} \rightarrow$ $\mathrm{CH}_{2} \mathrm{R}+\mathrm{C}$, which requires free sites. Furthermore, at low temperature chain growth is inhibited by one hydrogenation step, i.e. $\mathrm{CHCHR}+\mathrm{H} \rightarrow \mathrm{CH}_{2} \mathrm{CHR}$, and limited by one dehydrogenation step, i.e. $\mathrm{CHCHR} \rightarrow \mathrm{CCHR}+\mathrm{H}$. Increasing the surface stability of $\mathrm{H}$ atoms, therefore, lowers the rate of hydrogenation and increases the rate of dehydrogenation reactions. This provides a rationale for the positive TDCGC for $\mathrm{H}$ at low temperature (Figure 
5). At high temperature, chain growth is limited by two hydrogenation reactions, i.e., $\mathrm{OH}+\mathrm{H}$

$\rightarrow \mathrm{H}_{2} \mathrm{O}$ and $\mathrm{CHCR}+\mathrm{H} \rightarrow \mathrm{CHCHR}$ with DCGC values of 0.06 and 0.13 , respectively, and one dehydrogenation reaction $(\mathrm{CHCHR} \rightarrow \mathrm{CCHR}+\mathrm{H}$; DCGC $=0.04)$ and inhibited by one hydrogenation reaction $(\mathrm{CR}+\mathrm{H} \rightarrow \mathrm{CHR}, \mathrm{DCGC}=-0.06)$. This would suggest that destabilizing $\mathrm{H}$ atoms at the surface results in faster hydrogenation reactions and higher chain-growth probability. However, the opposite is seen in Figure 5 with the TDCGC value being strongly negative for $\mathrm{H}$. This is because, at high temperature, destabilization of $\mathrm{H}$ results in a faster rate of $\mathrm{H}_{2}$ desorption, which results in a higher number of vacant sites. These vacant sites have a negative impact on chain growth, as they facilitate depolymerization. This is confirmed by DCGC value of the $\mathrm{CR} \rightarrow \mathrm{CH}_{2} \mathrm{R}+\mathrm{C}$ reaction (0.10). These results would suggests that increasing the $\mathrm{H}_{2}$ pressure would result in an increase of the chain-growth probability. Typically, the reaction order of the FT reaction with respect to $\mathrm{H}_{2}$ is positive. In our microkinetic model, the $\mathrm{H}_{2}$ reaction order is also positive, because more $\mathrm{H}$ atom on the surface remove $\mathrm{O}$ from the surface, allowing higher coverage with $\mathrm{CH}$ intermediates. This can in principle increase the amount of methane and higher hydrocarbons produced. From our kinetic analysis, we predict that the chain-growth probability will be increased in such case, as the increased $\mathrm{H}$ coverage will suppress the rate of chain depolymerization. All these results emphasize the critical role of the coverage of $\mathrm{H}$ and free sites on the chain-growth mechanism during the FT reaction. The optimum in chainprobability finds its origin in Sabatier behavior. At low temperature, chain growth is limited by a lack of surface vacancies limiting the dehydrogenation step of a reaction intermediate, while at high temperature chain depolymerization occurs due to the increased number of surface sites. Overall, we infer that a necessary condition for the production of long hydrocarbon chains in the FT reaction is high surface coverage to suppress chain depolymerization. The H surface coverage also plays an important role in chain growth as 
hydrogenation and dehydrogenation steps are key in the interconversion of the growing chains for the next coupling step.

\section{Conclusions}

Microkinetics simulations of the complex FT reaction provide detailed insight into the elementary reaction steps that control the $\mathrm{CO}$ conversion rate and the chain-growth probability, a key selectivity parameter in commercial FT technology. Chain growth in the FT reaction on stepped $\mathrm{Ru}$ surfaces proceeds via coupling of $\mathrm{CH}$ and $\mathrm{CR}$ surface intermediates. Essential to the growth mechanism are $\mathrm{C}-\mathrm{H}$ dehydrogenation and $\mathrm{C}$ hydrogenation steps, whose kinetic consequences have been examined by formulating two novel kinetic concepts, the degree of chain-growth probability control and the thermodynamic degree of chain-growth probability control. These concepts are based on Campbell's degree of rate control. For Ru the CO conversion rate is controlled by the removal of $\mathrm{O}$ atoms from the catalytic surface. The Sabatier maximum of the $\mathrm{CO}$ conversion rate is predominantly determined by the surface coverage. Chain-growth probability shows a maximum at lower temperature than the $\mathrm{CO}$ conversion maximum. The steps that control chain-growth probability are different from those that control the overall rate. These are necessarily decoupled as chain growth cannot be rate-controlling in the overall FT process. Below the optimum for obtaining long hydrocarbon chains, the reaction is limited by the high total surface coverage: in the absence of sufficient vacancies the $\mathrm{CHCHR} \rightarrow \mathrm{CCHR}+\mathrm{H}$ reaction is slowed down. Beyond the optimum in chain-growth probability, $\mathrm{CHCR}+\mathrm{H} \rightarrow$ $\mathrm{CHCHR}$ and $\mathrm{OH}+\mathrm{H} \rightarrow \mathrm{H}_{2} \mathrm{O}$ limit the chain-growth process. The thermodynamic degree of chain-growth probability control emphasizes the critical role of the $\mathrm{H}$ and free-site coverage and shows that at high temperature chain depolymerization contributes to the decreased 
chain-growth probability. That is to say, during the FT reaction chain growth is much faster than chain depolymerization, which ensures high chain-growth probability. The chain-growth rate is also fast compared to chain-growth termination and compared to the steps that control the overall $\mathrm{CO}$ conversion rate, which are $\mathrm{O}$ removal steps for $\mathrm{Ru}$. 


\section{References}

1. Van Der Laan, G. P.; Beenackers, A. A. C. M., Kinetics and Selectivity of the Fischer-Tropsch Synthesis: A Literature Review. Catalysis Reviews 1999, 41, 255-318.

2. Adesina, A. A., Hydrocarbon Synthesis Via Fischer-Tropsch Reaction: Travails and Triumphs. Applied Catalysis A: General 1996, 138, 345-367.

3. van Steen, E.; Schulz, H., Polymerisation Kinetics of the Fischer-Tropsch Co Hydrogenation Using Iron and Cobalt Based Catalysts. Applied Catalysis A: General 1999, 186, 309-320.

4. Steynberg, A. P., Chapter 1 - Introduction to Fischer-Tropsch Technology. In Studies in Surface Science and Catalysis, André, S.; Mark, D., Eds. Elsevier: 2004; Vol. Volume 152, pp 1-63.

5. Filot, I. A. W.; van Santen, R. A.; Hensen, E. J. M., The Optimally Performing Fischer-Tropsch Catalyst. Angew. Chem. Int. Ed. 2014, DOI: 10.1002/anie.201406521.

6. Kozuch, S.; Shaik, S., A Combined Kinetic-Quantum Mechanical Model for Assessment of Catalytic Cycles: Application to Cross-Coupling and Heck Reactions. J. Am. Chem. Soc. 2006, 128, 3355-3365.

7. Kozuch, S.; Shaik, S., Kinetic-Quantum Chemical Model for Catalytic Cycles: The Haber-Bosch Process and the Effect of Reagent Concentration. J. Phys. Chem. A 2008, 112, 6032-6041.

8. van Santen, R. A.; Ciobîcă, I. M.; van Steen, E.; Ghouri, M. M., Chapter 3 - Mechanistic Issues in Fischer-Tropsch Catalysis. In Advances in Catalysis, Bruce, C. G.; Helmut, K., Eds. Academic Press: 2011; Vol. Volume 54, pp 127-187.

9. van Santen, R. A.; Ghouri, M.; Hensen, E. M. J., Microkinetics of Oxygenate Formation in the Fischer-Tropsch Reaction. Phys. Chem. Chem. Phys. 2014, 16, 10041-10058.

10. van Santen, R. A.; Ghouri, M. M.; Shetty, S.; Hensen, E. J. M., Structure Sensitivity of the Fischer-Tropsch Reaction; Molecular Kinetics Simulations. Catalysis Science \& Technology 2011, 1, 891-911.

11. Van Santen, R. A.; Markvoort, A. J.; Filot, I. A. W.; Ghouri, M. M.; Hensen, E. J. M., Mechanism and Microkinetics of the Fischer-Tropsch Reaction. Phys. Chem. Chem. Phys. 2013, 15, 17038-17063.

12. van Santen, R. A.; Markvoort, A. J.; Ghouri, M. M.; Hilbers, P. A. J.; Hensen, E. J. M., Monomer Formation Model Versus Chain Growth Model of the Fischer-Tropsch Reaction. J. Phys. Chem. C 2013, 117, 4488-4504.

13. van Santen, R. A.; Markvoort, A. J., Chain Growth by Co Insertion in the Fischer-Tropsch Reaction. ChemCatChem 2013, 5, 3384-3397.

14. Torres Galvis, H. M.; Bitter, J. H.; Davidian, T.; Ruitenbeek, M.; Dugulan, A. I.; de Jong, K. P., Iron Particle Size Effects for Direct Production of Lower Olefins from Synthesis Gas. Journal of the American Chemical Society 2012, 134, 16207-16215.

15. Stegelmann, C.; Andreasen, A.; Campbell, C. T., Degree of Rate Control: How Much the Energies of Intermediates and Transition States Control Rates. J. Am. Chem. Soc. 2009, 131, 80778082.

16. Stegelmann, C.; Schiødt, N. C.; Campbell, C. T.; Stoltze, P., Microkinetic Modeling of Ethylene Oxidation over Silver. Journal of Catalysis 2004, 221, 630-649.

17. Filot, I. A. W.; van Santen, R. A.; Hensen, E. J. M., Quantum Chemistry of the Fischer-Tropsch Reaction Catalysed by a Stepped Ruthenium Surface. Catalysis Science \& Technology 2014, 4, 31293140 .

18. Filot, I. A. W.; Broos, R. J. P.; van Rijn, J. P. M.; van Heugten, G. J. H. A.; van Santen, R. A.; Hensen, E. J. M., First-Principles-Based Microkinetics Simulations of Synthesis Gas Conversion on a Stepped Rhodium Surface. ACS Catalysis 2015, 5, 5453-5467.

19. Filot, I. A. W.; Zijlstra, B.; Hensen, E. J. M. http://www.mkmcxx.nl.

20. Wojciechowski, B. W., The Kinetics of the Fischer-Tropsch Synthesis. Catalysis Reviews 1988, 30, 629-702.

21. Zennaro, R.; Tagliabue, M.; Bartholomew, C. H., Kinetics of Fischer-Tropsch Synthesis on Titania-Supported Cobalt. Catalysis Today 2000, 58, 309-319. 
22. Schulz, H.; Claeys, M., Kinetic Modelling of Fischer-Tropsch Product Distributions. Applied Catalysis A: General 1999, 186, 91-107.

23. Filot, I. A.; van Santen, R. A.; Hensen, E. J., The Optimally Performing Fischer-Tropsch Catalyst. Angew Chem Int Ed Engl 2014, 53, 12746-12750. 


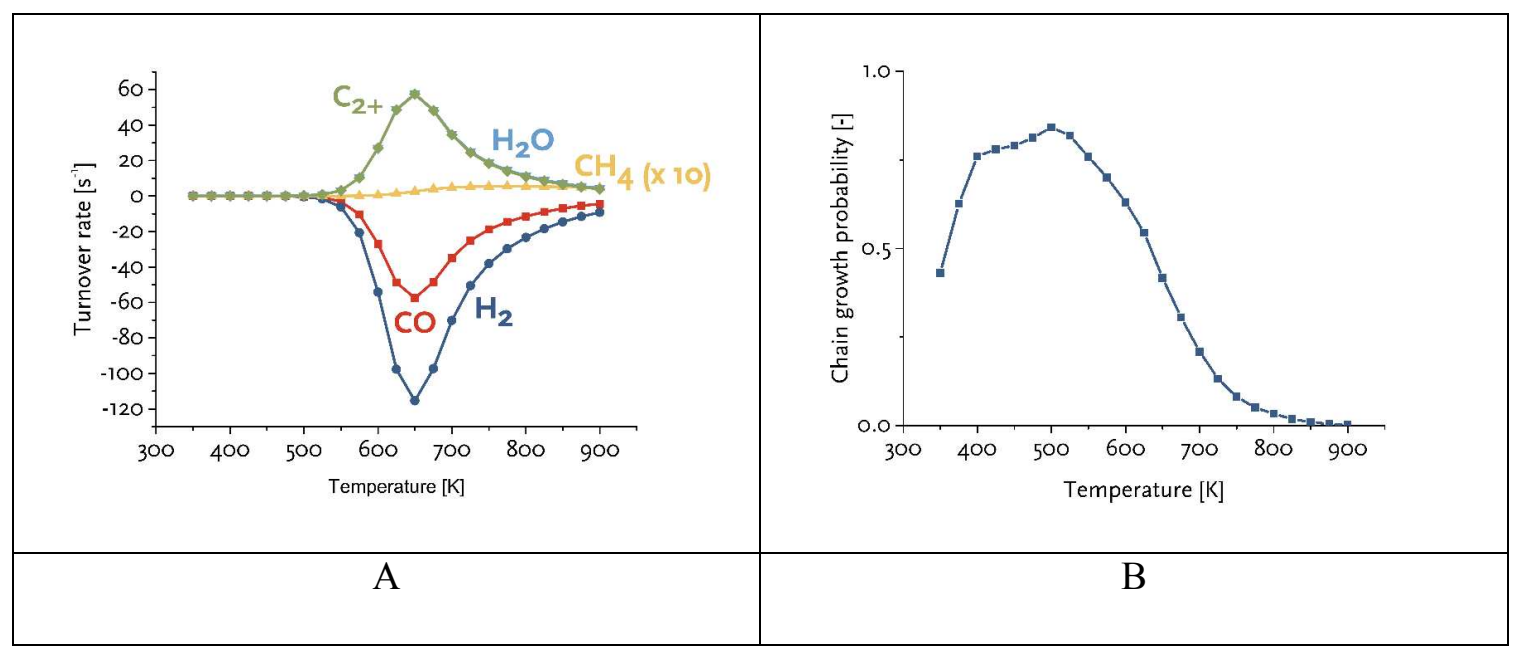

Figure 1: Microkinetics simulations of the FT reaction on stepped $\mathrm{Ru}$ at $\mathrm{p}=20 \mathrm{~atm}$ and a $\mathrm{H}_{2} / \mathrm{CO}$ ratio of 2 of $\mathrm{Ru}(11 \overline{2} 1)$ surface: (a) $\mathrm{CO}$ and $\mathrm{H}_{2}$ consumption rates and $\mathrm{CH}_{4}, \mathrm{H}_{2} \mathrm{O}$ and $\mathrm{C}_{2+}$ production rates as a function of temperature. Note that the $\mathrm{C}_{2+}$ trace overlaps the $\mathrm{H}_{2} \mathrm{O}$ trace. (b) The chain-growth probability as a function of temperature, displaying a maximum at $\sim 500 \mathrm{~K}$. 


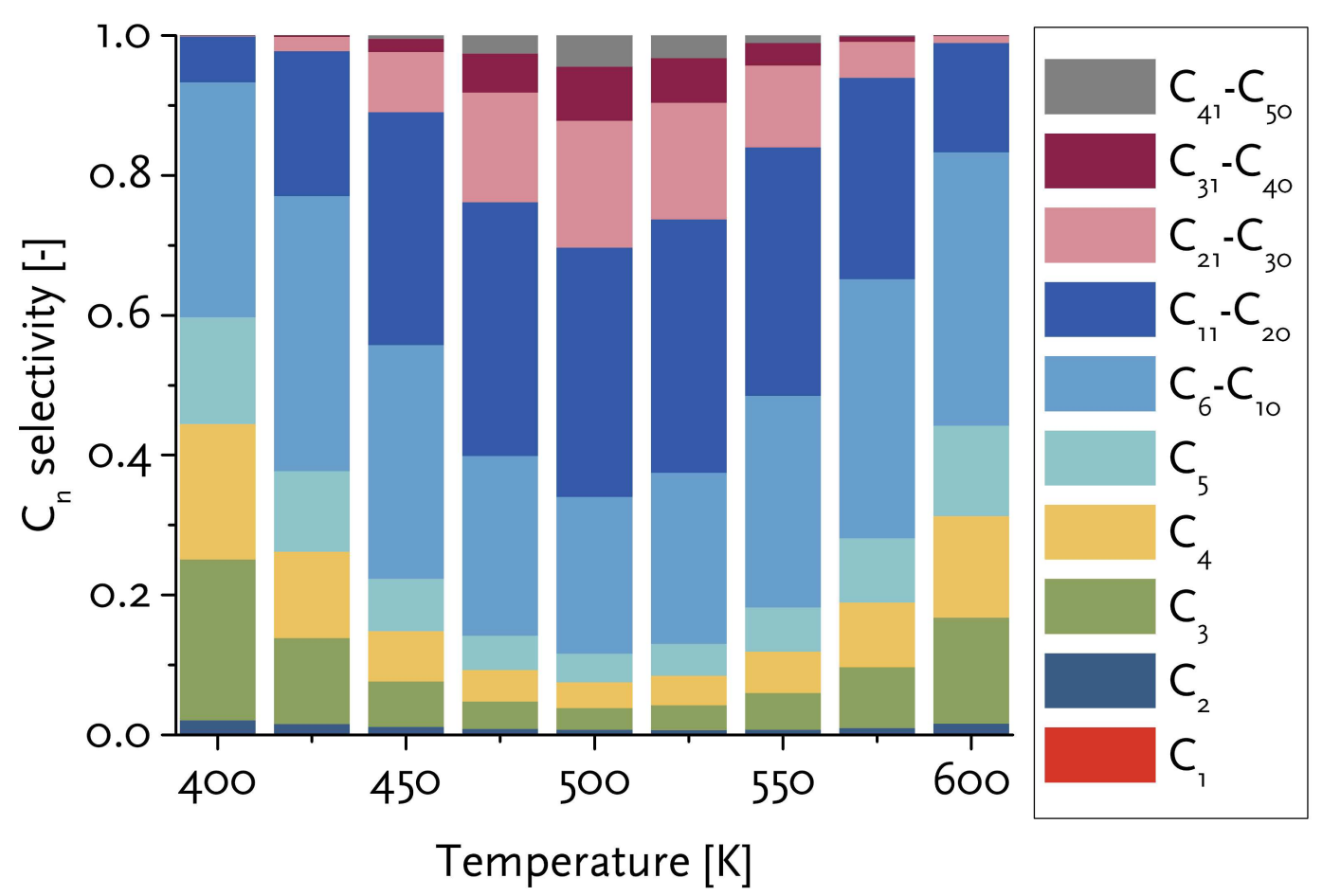

Figure 2: Hydrocarbon product selectivity for $\mathrm{C}_{1}-\mathrm{C}_{50}$ as a function of temperature. The selectivity to $\mathrm{C}_{40}+$ hydrocarbons is highest at $500 \mathrm{~K}$, consistent with the highest chain-growth probability determined at this temperature. Data for the FT reaction on stepped Ru at $p=20$ atm and a $\mathrm{H}_{2} / \mathrm{CO}$ ratio of 2 . 

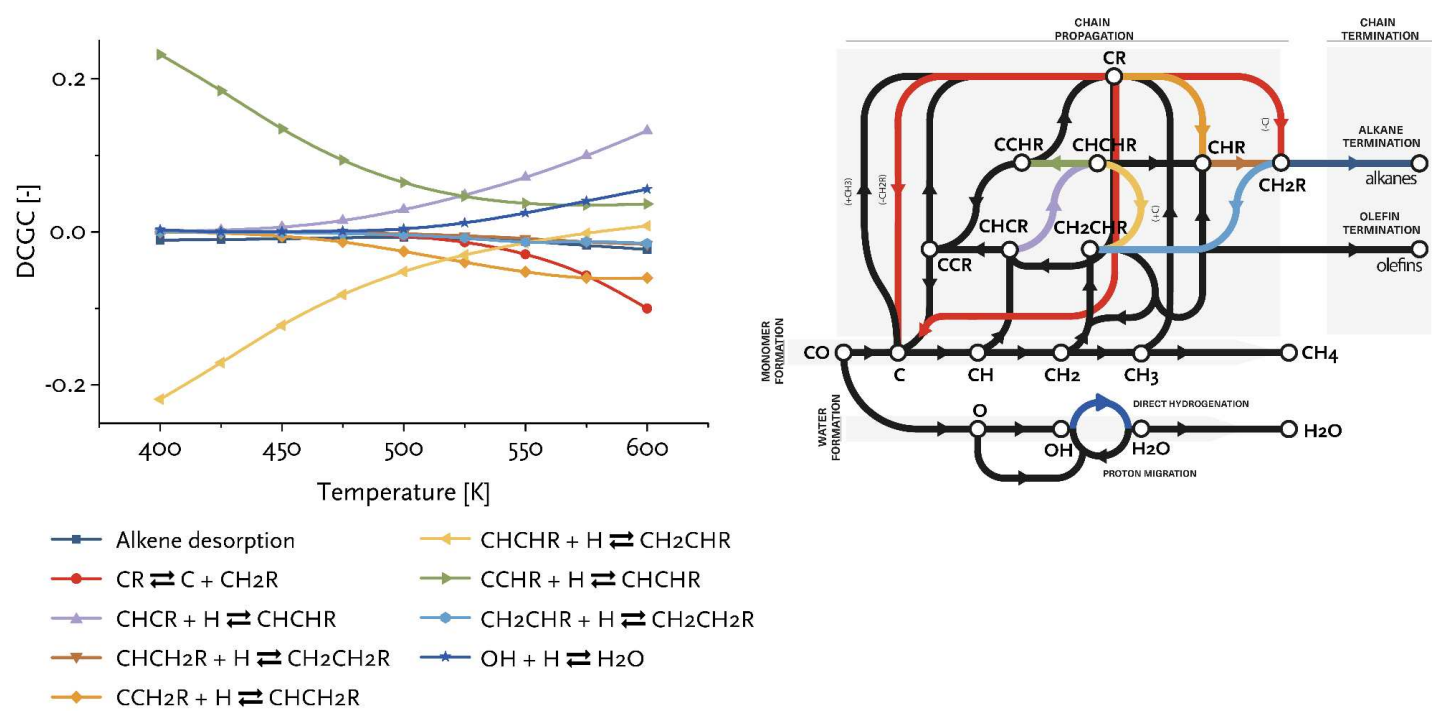

Figure 3: (a) Degree of chain-growth control (DCGC) as a function of temperature for relevant elementary reaction steps, whose DCGC value is larger than 0.01 . Positive values imply that decreasing barrier for an elementary reaction steps increases the chain-propagation probability. (b) Reaction network diagram of the relevant elementary reactions steps and the direction of chemical conversion. Data for the FT reaction on stepped Ru at $p=20 \mathrm{~atm}$ and a $\mathrm{H}_{2} / \mathrm{CO}$ ratio of 2 . 


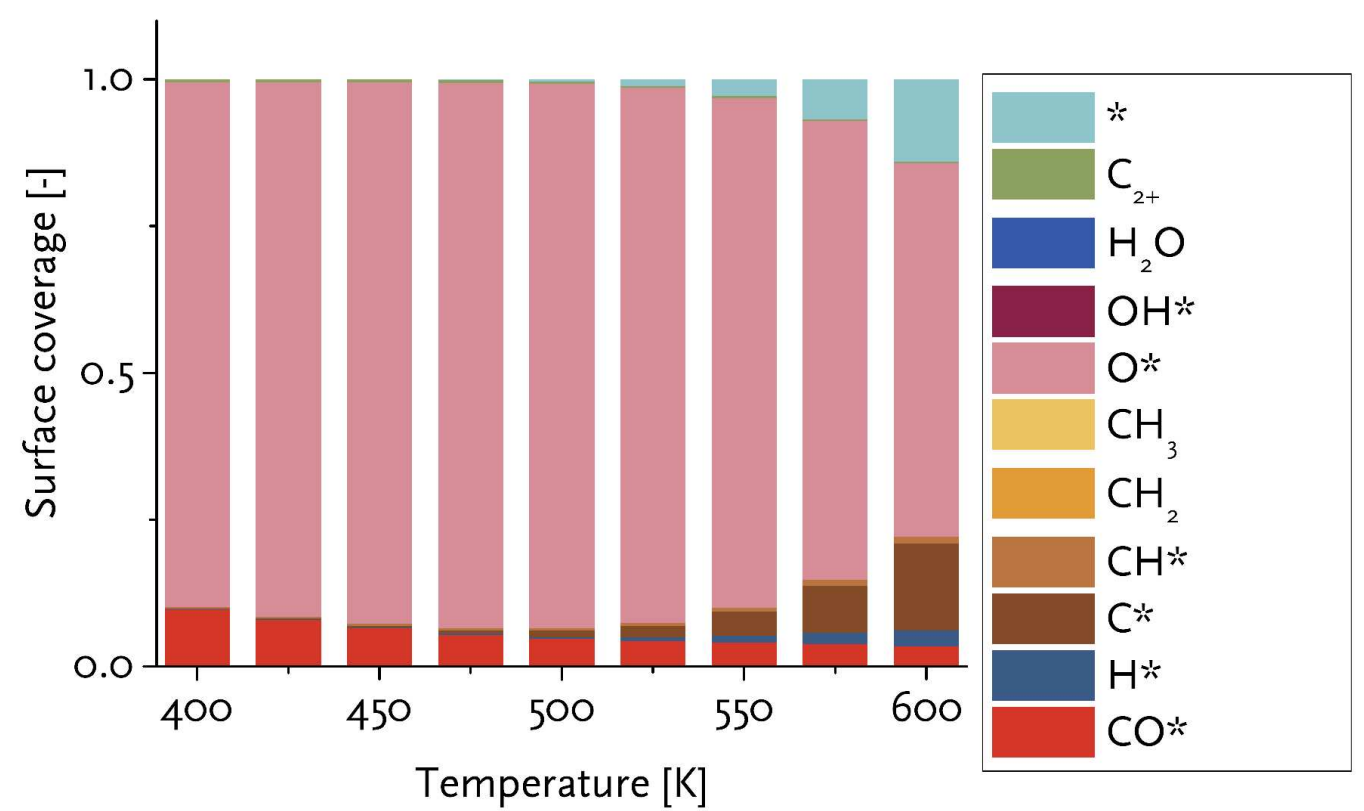

Figure 4: Surface coverage as a function of temperature for the FT reaction on stepped Ru at $\mathrm{p}=20 \mathrm{~atm}$ and $\mathrm{a} \mathrm{H}_{2} / \mathrm{CO}$ ratio of 2 . The total coverage of growing chains on the surface is around $3 \%$. The surface is predominantly covered with $\mathrm{O}$. 


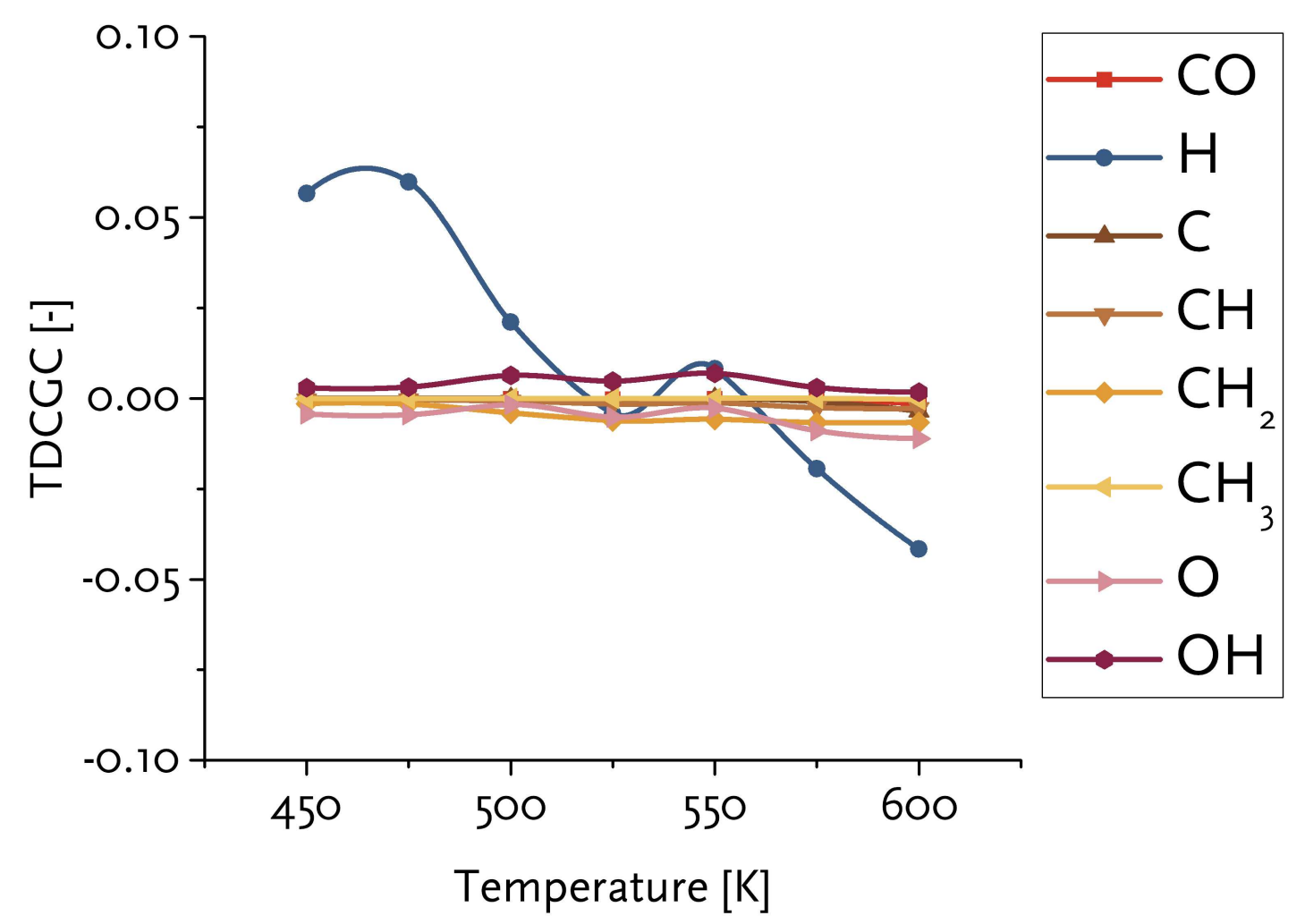

Figure 5: Thermodynamic degree of chain growth control (TDCGC) as a function of temperature. A positive value indicates that stabilizing this species on the surface results in a higher chain-propagation probability and vice versa. Data for the FT reaction on stepped Ru at $\mathrm{p}=20 \mathrm{~atm}$ and $\mathrm{a} \mathrm{H}_{2} / \mathrm{CO}$ ratio of 2 . 


\section{Supporting information}

\section{Kinetic aspects of chain growth in Fischer-Tropsch synthesis}

Ivo A.W. Filot, Bart Zijlstra, Robin J.P. Broos, Wei Chen, Robert Pestman, and Emiel J.M.

Hensen*

Laboratory of Inorganic Materials Chemistry, Schuit Institute of Catalysis, Department of Chemical Engineering and Chemistry, Eindhoven University of Technology, P.O. Box 513, 5600 MB, Eindhoven, The Netherlands

E-mail: e.j.m.hensen@tue.nl 
Table S1: List of all elementary reaction steps surfaces and their corresponding forward and backward activation energies used to model FT synthesis over $\mathrm{Ru}(11-21)$. The reported forward and reverse energies are in relation to the most stable states found for the reactants and products and include zeropoint-energy corrections.

\begin{tabular}{|c|c|c|c|}
\hline Index & Elementary reaction & Forward $E_{\text {act }}(\mathrm{kJ} / \mathrm{mol})$ & Backward $E_{\text {act }}(\mathrm{kJ} / \mathrm{mol})$ \\
\hline 1 & $\mathrm{CO}^{*}+* \rightarrow \mathrm{C}^{*}+\mathrm{O}^{*}$ & 65 & 90 \\
\hline 2 & $\mathrm{CO}^{*}+\mathrm{H}^{*} \rightarrow \mathrm{HCO}^{*}+*$ & 80 & 5 \\
\hline 3 & $\mathrm{HCO}^{*}+* \rightarrow \mathrm{CH}^{*}+\mathrm{O}^{*}$ & 45 & 129 \\
\hline 4 & $\mathrm{C}^{*}+\mathrm{H}^{*} \rightarrow \mathrm{CH}^{*}+*$ & 40 & 39 \\
\hline 5 & $\mathrm{CH}^{*}+\mathrm{H}^{*} \rightarrow \mathrm{CH}_{2}^{*}+*$ & 75 & 37 \\
\hline 6 & $\mathrm{CH}_{2} *+\mathrm{H}^{*} \rightarrow \mathrm{CH}_{3} *+*$ & 57 & 47 \\
\hline 7 & $\mathrm{CH}_{3} *+\mathrm{H}^{*} \rightarrow \mathrm{CH}_{4}+2^{*}$ & 94 & 57 \\
\hline 8 & $\mathrm{C}^{*}+\mathrm{C}^{*} \rightarrow \mathrm{CC}^{*}+{ }^{*}$ & 138 & 144 \\
\hline 9 & $\mathrm{C}^{*}+\mathrm{CH}^{*} \rightarrow \mathrm{CCH}^{*}+*$ & 129 & 75 \\
\hline 10 & $\mathrm{C}^{*}+\mathrm{CH}_{2} * \rightarrow \mathrm{CCH}_{2}{ }^{*}+*$ & not found & \\
\hline 11 & $\mathrm{C}^{*}+\mathrm{CH}_{3} * \rightarrow \mathrm{CCH}_{3}{ }^{*}+*$ & 92 & 116 \\
\hline 12 & $\mathrm{CH}^{*}+\mathrm{CH}^{*} \rightarrow \mathrm{CHCH}^{*}+*$ & 149 & 117 \\
\hline 13 & $\mathrm{CH}^{*}+\mathrm{CH}_{2} * \rightarrow \mathrm{CHCH}_{2}{ }^{*}+*$ & not found & \\
\hline 14 & $\mathrm{CH}^{*}+\mathrm{CH}_{3} * \rightarrow \mathrm{CHCH}_{3} *+*$ & not found & \\
\hline 15 & $\mathrm{CH}_{2} *+\mathrm{CH}_{2} * \rightarrow \mathrm{CH}_{2} \mathrm{CH}_{2} *+*$ & 54 & 60 \\
\hline 16 & $\mathrm{CH}_{2} *+\mathrm{CH}_{3} * \rightarrow \mathrm{CH}_{2} \mathrm{CH}_{3} *+*$ & not found & \\
\hline 17 & $\mathrm{CC}^{*}+\mathrm{H}^{*} \rightarrow \mathrm{CCH}^{*}+\mathrm{H}^{*}$ & 104 & 72 \\
\hline 18 & $\mathrm{CCH}^{*}+\mathrm{H}^{*} \rightarrow \mathrm{CCH}_{2}^{*}+*$ & 82 & 129 \\
\hline 19 & $\mathrm{CCH}_{2}{ }^{*}+\mathrm{H}^{*} \rightarrow \mathrm{CCH}_{3} *+*$ & 19 & 4 \\
\hline 20 & $\mathrm{CCH}^{*}+\mathrm{H}^{*} \rightarrow \mathrm{CHCH}^{*}+*$ & 140 & 162 \\
\hline 21 & $\mathrm{CCH}_{2}{ }^{*}+\mathrm{H}^{*} \rightarrow \mathrm{CHCH}_{2}{ }^{*}+*$ & 82 & 21 \\
\hline
\end{tabular}




\begin{tabular}{|c|c|c|c|}
\hline 22 & $\mathrm{CCH}_{3} *+\mathrm{H}^{*} \rightarrow \mathrm{CHCH}_{3}{ }^{*}+*$ & 82 & 8 \\
\hline 23 & $\mathrm{CHCH}^{*}+\mathrm{H}^{*} \rightarrow \mathrm{CHCH}_{2}{ }^{*}+*$ & 83 & 46 \\
\hline 24 & $\mathrm{CHCH}_{2} *+\mathrm{H}^{*} \rightarrow \mathrm{CHCH}_{3} *+*$ & 62 & 34 \\
\hline 25 & $\mathrm{CHCH}_{2} *+\mathrm{H}^{*} \rightarrow \mathrm{CH}_{2} \mathrm{CH}_{2} *+*$ & 45 & 42 \\
\hline 26 & $\mathrm{CHCH}_{3} *+\mathrm{H}^{*} \rightarrow \mathrm{CH}_{2} \mathrm{CH}_{3} *+*$ & 19 & 23 \\
\hline 27 & $\mathrm{CH}_{2} \mathrm{CH}_{2} *+\mathrm{H}^{*} \rightarrow \mathrm{CH}_{2} \mathrm{CH}_{3} *+*$ & 58 & 34 \\
\hline 28 & $\mathrm{CH}_{2} \mathrm{CH}_{3} *+\mathrm{H}^{*} \rightarrow \mathrm{CH}_{3} \mathrm{CH}_{3} *+*$ & 112 & 71 \\
\hline 29 & $\mathrm{O}^{*}+\mathrm{H}^{*} \rightarrow \mathrm{OH}^{*}+*$ & 97 & 49 \\
\hline 30 & $\mathrm{OH}^{*}+\mathrm{H}^{*} \rightarrow \mathrm{H}_{2} \mathrm{O}^{*}+*$ & 89 & 15 \\
\hline 31 & $2 \mathrm{OH}^{*} \rightarrow \mathrm{H}_{2} \mathrm{O}^{*}+\mathrm{O}^{*}$ & 54 & 11 \\
\hline
\end{tabular}




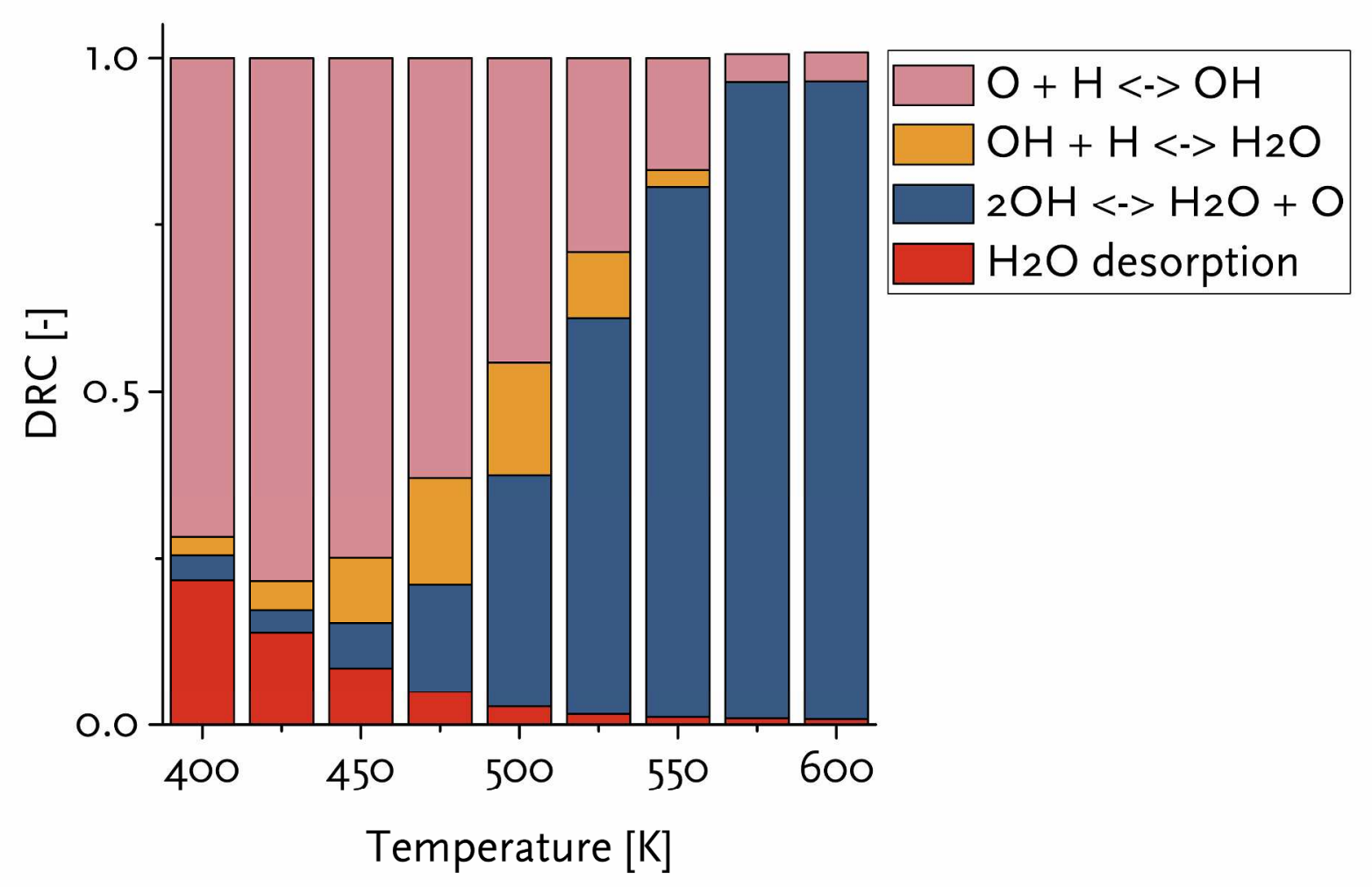

Figure S1: Degree of rate control for the microkinetics simulations of the stepped Ru surface at 20 atm and $\mathrm{H}_{2} / \mathrm{CO}=2$, exemplifying that under all conditions $\mathrm{O}$ removal from the surface is controlling the overall $\mathrm{CO}$ consumption rate. 